\title{
OUT-OF-CLASS LEARNING OPPORTUNITIES FOR ENGINEERING STUDENTS
}

\author{
Alidad Amirfazli \\ Department of Mechanical Engineering, York University, Toronto, ON, M3J 1P3, Canada \\ alidad2@yorku.ca
}

\section{INTRODUCTION}

The globalization of economy requires a globally savvy workforce (e.g. culturally sensitive, and technically aware of various engineering and research practices/resources). Engineering curriculum has a reputation for being a very demanding and intensive program compared to many other bachelor degree programs. This is mainly due to the nature of the discipline, i.e. the extent of the foundation materials needed, and to a certain degree due to accreditation requirements. This situation often results in engineering students to focus solely on the "formal" curriculum of their program during their studies. As such, engineering students seem to enjoy fewer opportunities to develop professional attributes such as leadership, cultural experiences, and teamwork especially in a non-engineering/interdisciplinary environment.

Recognizing that not all learning can take place in the classroom, or by a traditional curriculum, here various strategies with significant outof-class (or campus) learning is presented to address the shortcomings such as leadership, cultural and social awareness, and business or legal matters. Such gaps have been flagged as areas that need attention in various studies, e.g. [1].

\section{OUT-OF-CLASS LEARNING IDEAS}

Engineering programs can rectify the situation discussed in the Introduction by considering a suite of activities that if properly designed, will not add noticeably to the load of a typical engineering program. In this paper, three strategies of using student clubs, exchange programs, and special courses with significant out-of-class learning content, or an interdisciplinary delivery and participation will be presented as avenues for bridging the gaps identified above.

The author has been involved in any combinations of conceiving, designing, implementing, or encouraging of the ideas discussed in this paper. There has not been an attempt to systematically conduct a scholarly research on the topics discussed here, but instead this paper is meant to be a summary of experiences and observations made by the author about the presented ideas (i.e. a reflective work).

\section{Student Clubs}

Student clubs are usually fall within categories of specialist (e.g. robotics club, or SAE formula clubs) and generalist (e.g. debating club, investment club, chess club, etc.). The specialist clubs, although provide opportunities for leadership and teamwork development, they are by their nature focused mainly on somewhat narrow technical issues, and appeal to a particular student population. Furthermore, they seldom include students from varied backgrounds (e.g. a student group composed of engineering, commerce, and social sciences); as such leadership and teamwork opportunities are exercised within limits of students from the same background (hardly the case in a person's career). The "generalist" clubs provide many opportunities for students from different programs/backgrounds to mix, but their engineering context is usually limited or nonexistent. A middle ground may be struck. An example is the Engineers Without Boarder (EWB) [2]. Students in local chapters of the EWB can participate in developmental work in developing countries where they should not only use their technical abilities but also exercise them in a social and cultural context/setting by e.g. partnering with other NGOs; this provides valuable holistic learning opportunities. The range of activities can be placement overseas, fundraising, and education of larger population by e.g. attending annual conferences all having and technical/engineering context.

Another example of a student club with similar characteristics to EWB that combines technical as well as broader non-technical mandate and activities is the Energy Club at the University of Alberta in 2008 [3]. The club was mandated to be open to all students, and even the larger community, i.e. Edmonton. Within a technological/engineering context, i.e. energy systems, use, and production, the club was designed to be an unbiased forum for providing educational, leadership, and student engagement opportunities within the technical context of energy in a broad sense (i.e. energy policy, science, societal, environmental, and economics issues). The activities ranged from holding relevant movie nights, to technical speaker series, to career fairs, to field trips, to public engagement (panel discussions) where policy people and even local politicians attended. The "context" is what sets apart Energy Club and EWB from other "general interest" clubs, that can provide students with complementary skillsets stated earlier.

\section{Exchange Program}

Traditional exchange programs are usually centrally planned and student participation is somewhat ad hoc. Given the program load in engineering and issues with program accreditation, as well as employment opportunities over summer, exchange programs have not been usually popular. However, learning opportunities that will not only benefit technical education, but also will hone leadership and cultural/global attributes of students skills can be achieved by a locally (departmental level) planned exchange program. One such example is the exchange program between the Department of Mechanical Engineering (U of Alberta) and TU Bergakademie Freiberg in Germany. This exchange program included student participation in a purposely designed intensive course about renewable energy technologies over 5 weeks. About $50 \%$ of students also had the opportunity to do an internship in a company or a research institute for a further $\sim 12$ weeks. Many of the 100 students who have participated in such an exchange since 2006/07 have expressed experiencing a once in a lifetime learning opportunity. The important features of planning and execution of the program as was designed by the author were: (1) finding a champion at the host institute; (2) working with the host institute champion in developing a curriculum (and evaluation scheme) that will be acceptable as one of the technical electives for the purpose of accreditation of home institute; (3) sourcing grants and raising funds for student travel, accommodation, and scholarships (the scholarship is very important to (a) soften the loss of income as a result of not working over summer; (b) attracting the best students); (4) developing a selection criteria for participants based on academic achievement, demonstrated interest in the topic of the course to be taken aboard, and general attributes and background interests of the students (examination of resume); (5) coordinating with the international office of both institutes about liability and immigration issues; (6) it is recommended that $3^{\text {rd }}$ year students to be the main participants so there is a certain level of maturity (also useful for internship), as well as returning students can share their experiences with those who did not participate (peer learning); (7) predeparture briefing, e.g. cultural, expectation, and evaluation; (8) interim on-site visit to deal with any issues or obtain feedback; (9) Post-return reporting for the purpose of recordkeeping and improvements as well as accreditation process; (10) we found that beyond the first year there was no need for advertising, as word of mouth of extremely satisfied students, sustained awareness.

\section{Multidisciplinary Courses and Instruction}

For brevity and due to page limitation, the reader is directed to the paper 105 in this proceeding for a detailed discussion on the topic; only the four main enabling factors for offering a multidisciplinary courses is provided here. (1) resources - instruction and administration come at a cost. (2) the team - if the members do not know one another or cannot be identified through a course organizer's networks, they must be "recruited". This would probably require the involvement of a senior colleague, such as a Dean, to do the "call for volunteers". (3) staff support - the myriad administrative details of offering and delivering a course must be attended to. (4) most importantly, the course needs a "champion" - someone who takes responsibility for starting the processes and kick-starting them when they stall.

\section{REFERENCES}

1. ASME Vision 2030 - Creating the Future of Mechanical Engineering Education, a report from ASME Education Center, 2011.

2. www.ewb.ca (available online April 30, 2014)

3. www.energyclub.ca (available online April 30, 2014) 